\title{
Seagrass beds and intertidal invertebrates: an experimental test of the role of habitat structure
}

\author{
P. G. Cardoso $\cdot$ D. Raffaelli $\cdot$ M. A. Pardal
}

Received: 27 January 2006/Revised: 26 June 2006/ Accepted: 31 July 2006/Published online: 25 September 2006 (C) Springer Science+Business Media B.V. 2006

\begin{abstract}
The majority of field experiments have been carried out on relatively small spatial and short temporal scales, but some of the most interesting ecological processes operate at much larger scales. However, large-scale experiments appropriate to the landscape, often have to be carried out with minimal plot replication and hence reduced statistical power. Here, we report the results of such a large scale, un-replicated field experiment on the Mondego estuary, Portugal, which nevertheless provides compelling evidence of the importance of habitat structure for invertebrate community composition and dynamics. In this estuary, seagrass beds have suffered a dramatic decline over the last 20 years, associated with changes in invertebrate assemblages. In addition, the most abundant species in the system, Hydrobia ulvae, displays distinctly different population structures in those sites. The aim of the field experiment was to test the hypothesis that
\end{abstract}

Handling editor: K. Martens

P. G. Cardoso $(\bowtie) \cdot$ M. A. Pardal

Department of Zoology, IMAR - Institute of Marine

Research, University of Coimbra, 3004-517 Coimbra,

Portugal

e-mail: gcardoso@ci.uc.pt

D. Raffaelli

Environment Department, University of York,

Heslington, York YO10 5DD, UK these differences are related to enhanced survival of snails due to protection from avian or fish predators so that they can grow to larger body sizes in the more complex habitat provided by seagrass. We tested this hypothesis through a large-scale experiment using artificial seagrass beds over a 12-month period. Adult snail densities were higher in the artificial bed plots compared to controls. However, these differences emerged only slowly, related to snail growth rate. This suggests that protection from epibenthic predators can have a significant effect on population structure and hence biomass and productivity of key species in this system. However, the invertebrate assemblage in artificial seagrass plots and the natural seagrass bed, remained statistically separate by the end of the experiment.

Keywords Zostera noltii $\cdot$ Artificial seagrass unit $\cdot$ Habitat structure $\cdot$ Hydrobia ulvae

\section{Introduction}

Dominant taxa such as fields of tube worms, mounds of lugworms and beds of mussels and seagrasses generate landscape-scale complexity in many intertidal areas. The invertebrate assemblages associated with such landscapes are often qualitatively and quantitatively different from adjacent areas lacking these dominants due to 
differences in the hydrodynamic, sediment and/or predation climate (Commito \& Boncavage, 1989; Dittmann, 1990; Flach, 1992; Raffaelli et al., 1998; Commito \& Dankers, 2001; Flach \& Tamaki, 2001; Cardoso et al., 2004). Evidence of the overriding role of the dominant has been most compelling when mimics of the habitat structure normally created by such taxa have been used in controlled manipulative field experiments for tube fields and mussel beds (e.g. Ragnarsson \& Raffaelli, 1999, 2001). However, such experimental set-ups are necessarily on a relatively small spatial scale, due to the need to replicate treatment plots as well as the enormous effort required to assemble the mimic structures. The effects of spatial scale (extent) on the interpretation of the results from such experiments are not well understood because few experiments of this type can accommodate a wide range of spatial scales. Where manipulative experiments have been carried out at the larger scales appropriate to the landscape features of interest, replication has been necessarily sacrificed at the expense of realism (e.g. Paine's early experiments on starfish removal in Washington, USA and limpet removals on the Isle of Man, UK) and the results remain convincing (reviewed in Raffaelli \& Moller, 2000).

Here, we adopt a large-scale approach to the role of a dominant taxon of many intertidal and shallow sublittoral areas around the European coast, the seagrass Zostera noltii. At a well-documented site, the Mondego estuary, Portugal, previous research has shown that seagrass has become confined in recent years to the outer reach of the estuary due to extensive eutrophication in the inner parts (Marques et al., 1997; Cardoso et al., 2002, 2004; Marques et al., 2003; Pardal et al., 2004). The general macrofaunal assemblage in seagrass beds and in those areas from where seagrass has disappeared are distinctly different (Dolbeth et al., 2003; Marques et al., 2003; Cardoso et al., 2004; Pardal et al., 2004), and the most abundant species, the mudsnail Hydrobia ulvae, has different population structures in seagrass and non-seagrass habitats (Lillebø et al., 1999; Cardoso et al., 2002, 2005). Specifically, larger sized Hydrobia do not occur at non-seagrass sites. The between-site differences in population structure of Hydrobia do not appear to be due to differences in the incidence of parasites that induce gigantism (cf Huxham et al., 1995) and are more likely related to enhanced survival (due to protection from avian or fish predators) of snails to larger size classes in the more complex habitat provided by seagrass (Cardoso et al., 2002). In order to explore these hypotheses, large-scale plots of seagrass mimics were set up in non-seagrass areas and their assemblages and the population structure of Hydrobia compared with adjacent non-mimic plots over a 12-month period.

\section{Materials and methods}

The Mondego estuary is located on the Atlantic coast of Portugal $\left(40^{\circ} 08 \mathrm{~N}, 8^{\circ} 50 \mathrm{~W}\right)$ and comprises two contrasting arms, northern and southern, separated by Murraceira island, formed by the deposition of detrital materials transported by the river, as the river flood-plain (Fig. 1). During the last two decades, this estuary has experienced significant eutrophication leading to an overall increase in primary production and to a progressive replacement of seagrass Zostera noltii by opportunistic green macroalgae (Lilleb $\varnothing$ et al., 1999; Pardal et al., 2000, 2004; Martins et al., 2001; Cardoso et al., 2002, 2004; Dolbeth et al., 2003; Marques et al., 2003). Three distinct zones can be recognised in the southern arm: an outer estuary zone with a seagrass (Zostera noltii) bed, an innermost zone, which is the most eutrophic area (here termed "Arm") and an intermediate area (here termed "Gala") in between. At the time of the experiment, the eutrophic and intermediate zones, had no seagrass, but in the mid-1980s Zostera noltii occupied the entire southern arm covering almost 15 ha. Since the beginning of the 1990s, with increasing eutrophication, the extent of the seagrass bed was reduced to the small zone (0.9 ha in 2000) located downstream (Pardal et al., 2004; Cardoso et al., 2005).

In each of the two zones, a single artificial seagrass unit (ASU) (plot size $=2 \times 2 \mathrm{~m}$ ) was established in late September 2003. This size of plot was based on a balance between realism (simulation of a real seagrass bed) and resources 
Fig. 1 Location of the sampling areas in the south arm of the Mondego estuary

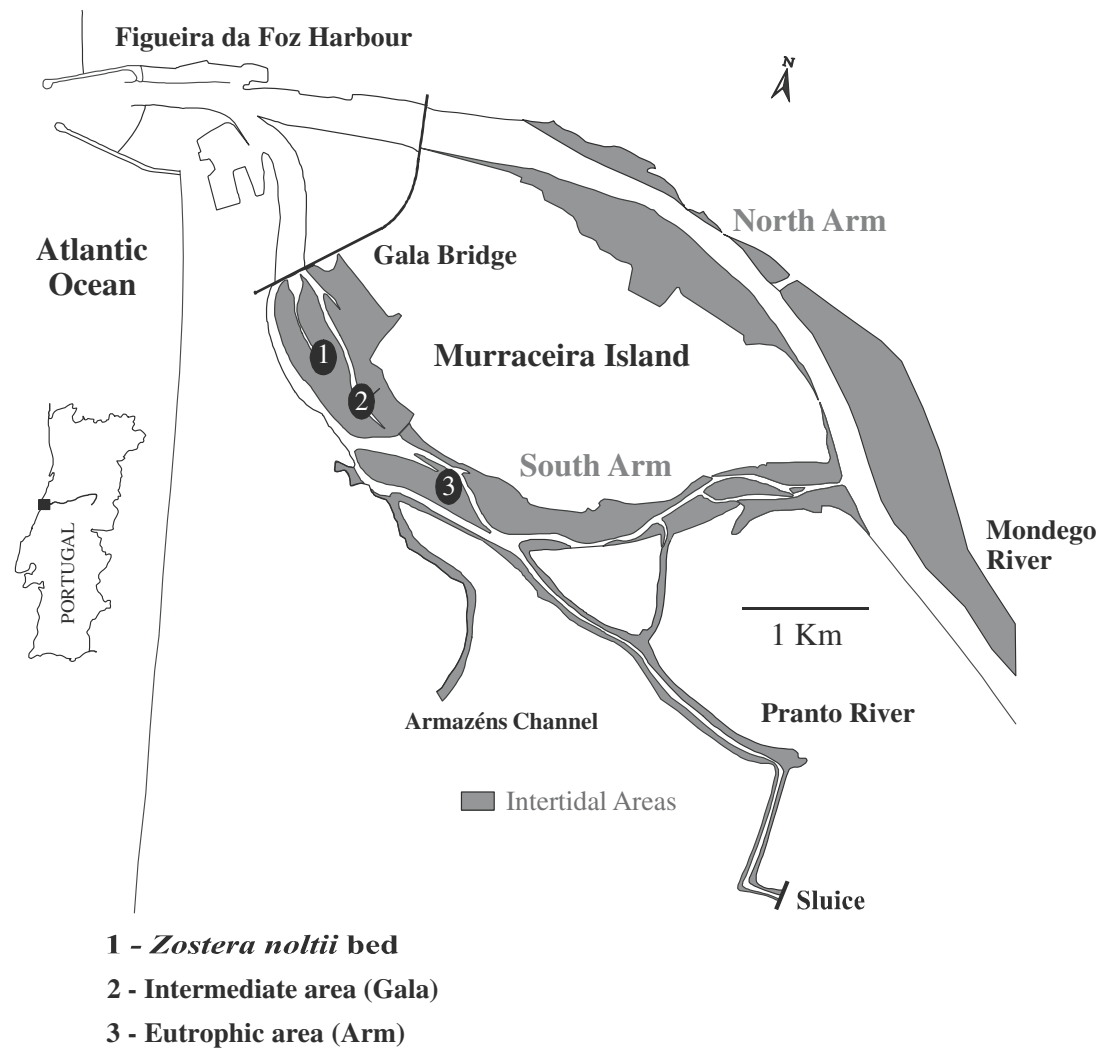

(person-power and funding). By virtue of their large size, both ASUs required almost 1 month to construct (involving several persons), so that replication of ASUs of this large plot size was not feasible. The majority of field experiments in the literature have been carried out on relatively small spatial and short temporal scales (Raffaelli \& Moller, 2000) but some of the most interesting and challenging ecological processes operate at much larger scales. If experiments are conducted on inappropriate scales, the outcomes may be meaningless, however well replicated. Each ASU comprised 3,000 artificial shoots $\left(\sim 750\right.$ shoots $\mathrm{m}^{-2}$, equivalent to those found in natural density $Z$. noltii bed). Each "seagrass" shoot consisted of five strips of 3-4 mm wide and $20 \mathrm{~cm}$ green plastic ribbon similar to $Z$. noltii leaves. The shoots were anchored to the sediment with corkscrewed wire, penetrating several centimetres into the sediment and mimicking a natural seagrass habitat. Additionally, in each experimental area, a control (treatment clear of artificial seagrass) was also established. In total, there were four treatments:
Gala artificial Zostera, Gala control, Arm artificial Zostera and Arm control. In addition there was a reference site (undisturbed Zostera noltii bed) and its control (unvegetated sediment adjacent to the Zostera bed-Z. noltii out). The experiment was set up in September 2003 at low tide and ran for 1 year. During this period, the plots were sampled on four occasions (winter-09/01/04, spring-10/ 03/04, summer-05/07/04 and fall-18/10/04). The duration of the experiment was based on the knowledge that Hydrobia would require at least 9 months to grow to its adult body size $(>1.5 \mathrm{~mm}$ width) (Cardoso et al., 2002) and hence the experiment should run for at least 9-12 months. If the experiment would run for a shorter period of time, probably, the effects of the treatment would not be visible. On each occasion and in each experimental area, three replicate cores were taken from the middle of each treatment plot, (avoiding the same spot subsequently), and also in the natural seagrass bed, using a $13-\mathrm{cm}$ diameter corer to a depth of $15 \mathrm{~cm}$. Additionally, we measured the sediment height within the artificial 
seagrass plots relative to the adjacent sand with a ruler and took sediment samples with a small syringe to $4 \mathrm{~cm}$ depth $(n=3)$ for organic matter estimation. All samples were washed in estuarine water through a $500 \mu \mathrm{m}$ mesh and the fauna retained preserved in $4 \%$ buffered formalin and later transferred to $70 \%$ ethanol.

All macrofauna were identified to the lowest possible taxon and counted. Macroalgae included in the sediment cores were picked out for later determination of biomass determined as ash free dry weight (AFDW) after oven drying at $60^{\circ} \mathrm{C}$ for $72 \mathrm{~h}$ and combustion at $450^{\circ} \mathrm{C}$ for $8 \mathrm{~h}$. The same procedure was used to quantify the organic matter content of the sediment.

All Hydrobia ulvae were counted and measured (maximum width-MW) and grouped in different age/size classes (juveniles $<1 \mathrm{~mm}$; young individuals 1-1.5 mm; adults $>1.5 \mathrm{~mm}$ ) (Anderson, 1971; Planas \& Mora, 1987; Cardoso et al., 2002).

Multivariate analysis of the macrofaunal assemblages

Faunal assemblages were compared using nonmetric Multi Dimensional Scaling (MDS) on square root transformed data (Clarke \& Warwick, 2001; Clarke \& Gorley, 2001). Because Hydrobia ulvae dominated all samples it was excluded from the MDS analysis. It should be noted that because there is no replication of plots within a site, any between-plot differences observed reflect just that: plot differences. This is a necessary feature of many large-scale experiments (Raffaelli \& Moller, 2000).

\section{Results}

\section{Macroalgal biomass}

At both experimental sites, there was greater biomass of green macroalgae in the artificial plots compared to the controls, with slightly more in the Arm artificial seagrass plot than in the Gala plot (Fig. 2). Biomass increased gradually throughout the sampling period reaching the
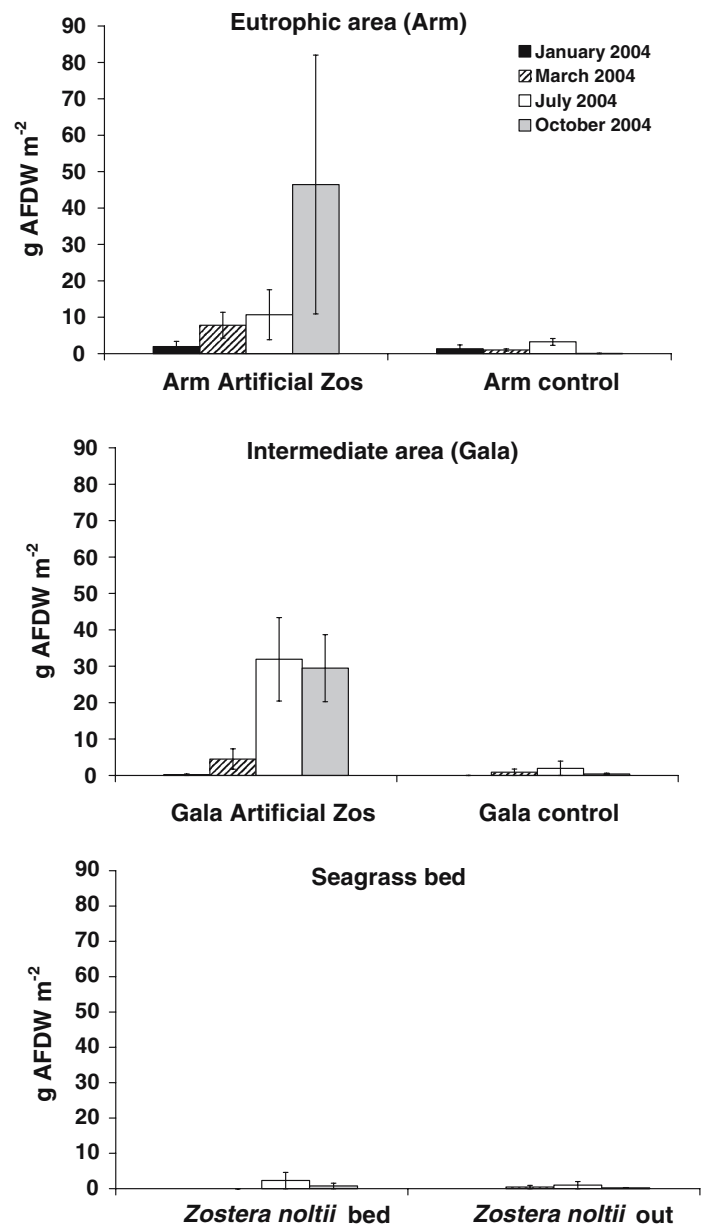

Fig. 2 Variation of green macroalgal biomass \pm standard error (SE) in the three sampling areas

highest values in July in the Gala artificial seagrass plot and in October for the Arm plot. In the natural seagrass bed, the biomass of green macroalgae was insignificant.

Organic matter content and deposition of sediment

The percentage of organic matter was generally greater in the artificial plots than in the controls (Fig. 3). This difference was more pronounced at the eutrophic site (Arm), especially for March and July, when we observed statistical differences between the artificial plot and the control (March, $t$-test, $t_{3}=10.14, P<0.05$; July, $t$-test, $t_{3}=12.71$, $P<0.05)$. In October, we recorded a marked 

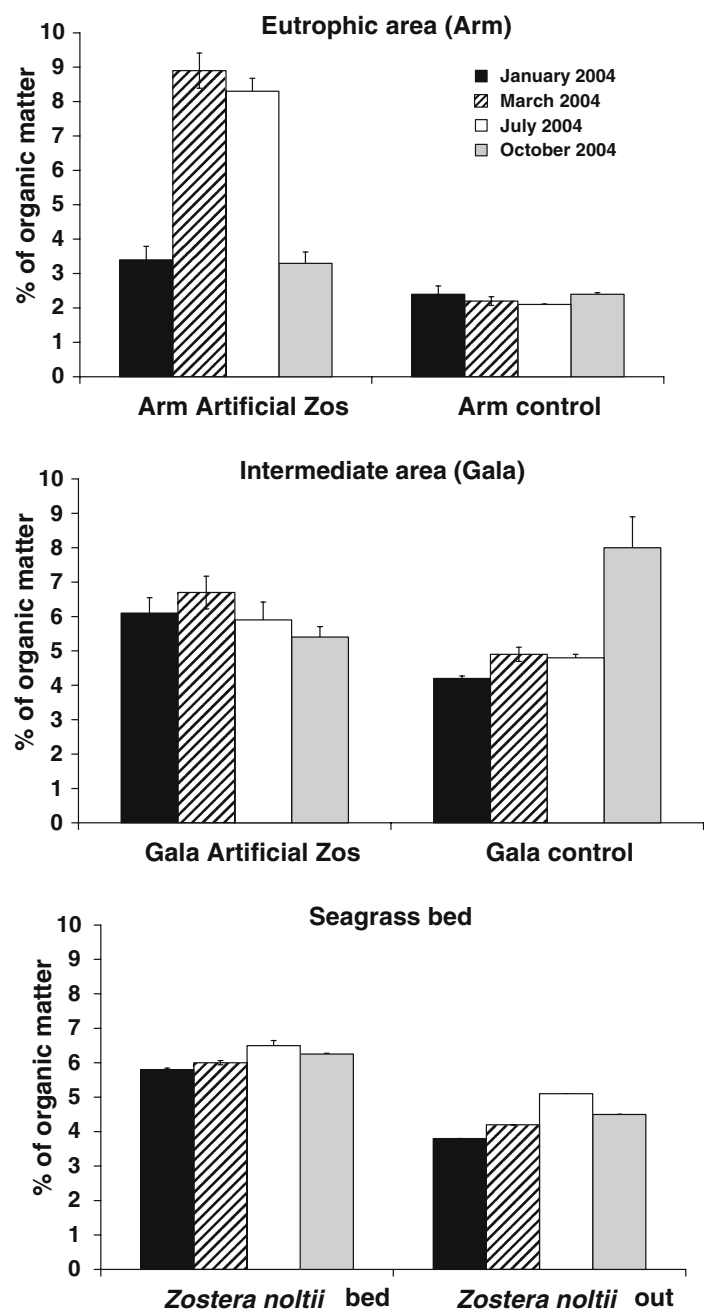

Fig. 3 Variation of the organic matter content of the sediment \pm standard error (SE) in the three sampling areas

reduction in organic matter content in the Arm artificial plot, probably due to high freshwater flows in that area, which washed out large amounts of sediment. The organic matter content in the natural seagrass bed was similar to that in the Gala artificial plot (Fig. 3). The organic matter content of the Gala control sediments was naturally greater than that of the Arm control, reflecting the muddy sediments of Gala and the more sandy sediments of the Arm.

Sediment accumulated dramatically in both of the artificial plots, being slightly higher in the Gala artificial plot $(6-8 \mathrm{~cm})$ than in Arm artificial plot $(4-9 \mathrm{~cm})$.
Hydrobia ulvae population density and structure

In the Arm area, there were no differences in snail density between the artificial plots and control in January ( $t$-test, $\left.t_{4}=-0.91, P>0.05\right)$ and March ( $t$-test, $\left.t_{4}=-2.08, P>0.05\right)$, but density was higher in the artificial plot in July ( $t$-test, $\left.t_{4}=11.84, P<0.05\right)$, and lower in the artificial plot in October (Fig. 4). In the Gala area, densities of $H$. ulvae were always higher in the artificial plot than in the control, but declined progressively over time. In the $Z$. noltii bed, H. ulvae density was generally higher than in the adjacent unvegetated areas, being significant in January ( $t$-test, $\left.t_{6}=4.76, P<0.05\right)$, July $\left(t\right.$-test, $t_{6}=3.63$, $P<0.05)$ and October $\left(t\right.$-test, $t_{6}=2.93$, $P<0.05)$.

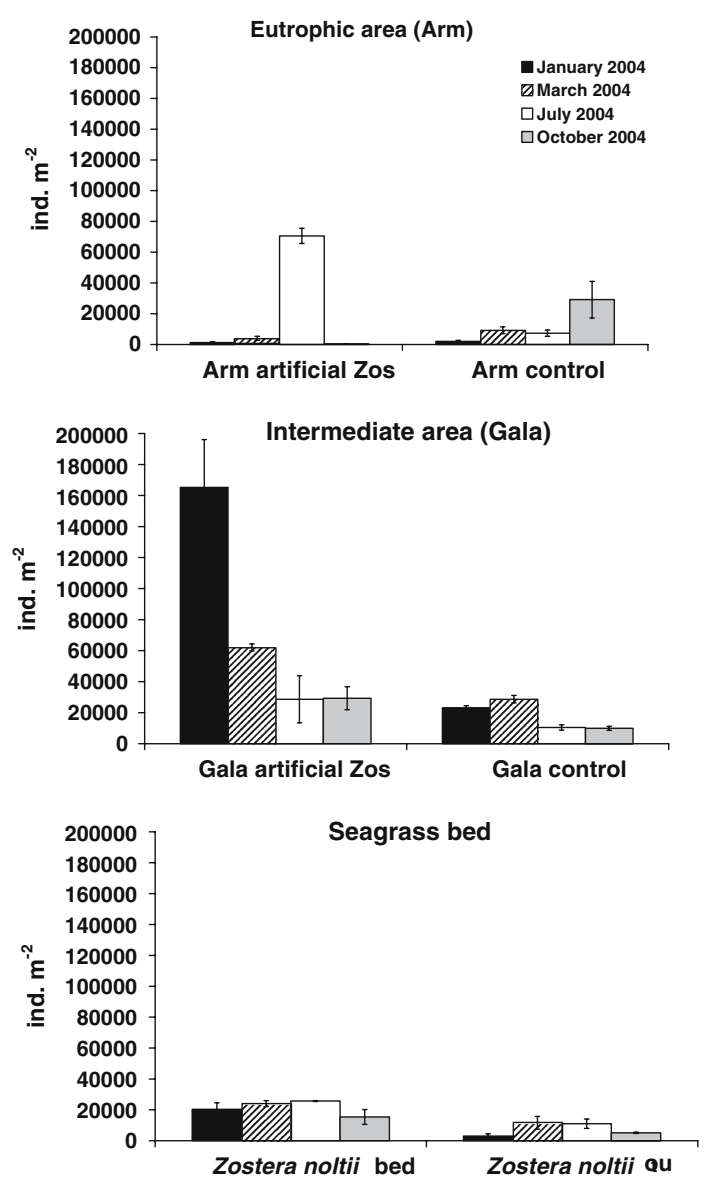

Fig. 4 Average Hydrobia ulvae density \pm standard error (SE) in the three sampling areas 
In both the Gala and Arm areas, the number of large individuals ( $>1.5 \mathrm{~mm} \mathrm{MW})$ in artificial seagrass and control plots was similar in January and March, with relatively larger numbers of adults appearing in artificial seagrass plots by July and October (Fig. 5). At the Arm site there were more adult snails in artificial plots compared to the control in July ( $t$-test, $\left.t_{4}=3.52, P<0.05\right)$ and at the Gala site in October, ( $t$-test, $t_{3}=4.38$, $P<0.05)$. The relatively slow emergence of differences between artificial and control plots is explained by the growth rates of Hydrobia at these sites (see below).

In October, large snails were reduced dramatically at the Arm site when the area experienced high flows ( $>1.5 \mathrm{~m} \mathrm{~s}^{-1}$ for some consecutive hours during several days) and hydraulic disturbance originating from a local industry discharge.
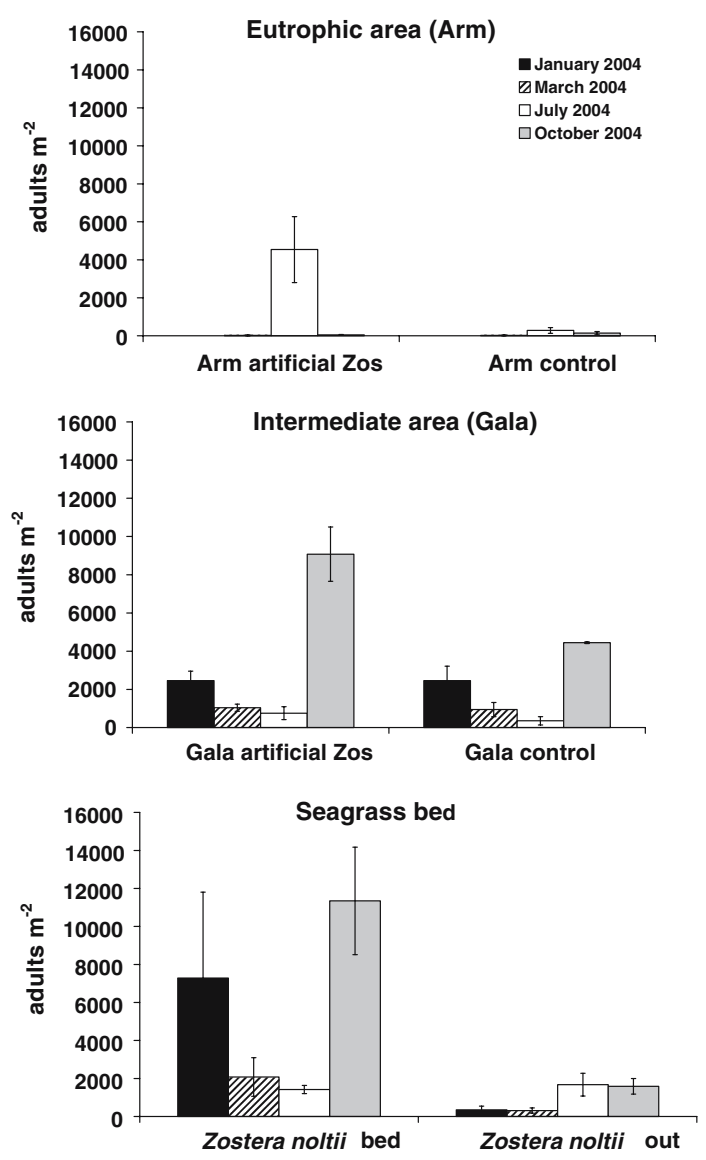

Fig. 5 Average Hydrobia ulvae adult density \pm standard error (SE) in the three sampling areas
The natural Zostera noltii bed generally had higher densities of adult snails compared to adjacent unvegetated areas.

Multivariate analysis of macrofaunal assemblages

Ordination plots (MDS) for each sampling occasion illustrate that neither the Gala nor the Arm artificial seagrass assemblages overlap with samples from the natural seagrass bed throughout the study period (Fig. 6), confirming that the primary experimental treatment was effective. However, the seagrass mimic assemblages were always differentiated from their matched control samples (Fig. 6), as was the case for the natural seagrass assemblages compared to those from the adjacent unvegetated sediments.

Inspection of the original Bray-Curtis similarity matrix reveals that, on average, the artificial seagrass assemblages at both experimental sites (Gala and Arm) became more similar to the natural seagrass bed over time, especially for Gala (increasing from $42 \%$ to $65 \%$ similarity) (Fig. 7). In opposite, the controls seem to become more isolated from the natural seagrass bed through time.

\section{Discussion}

Carrying out experiments at larger spatial scales often requires a trade-off with plot replication (Raffaelli \& Moller, 2000), reducing statistical power or as in the present case, obviating the application of inferential statistics such as ANOVA. The persuasiveness of such experiments rests in their more realistic spatial extents (our experiments had plots 20 times larger than those used in similar studies, Lee et al. 2001) and in their effect sizes (magnitude of difference between control and treatment plots). We could have made smaller, replicate artificial seagrass plots with the same resources (time, effort and funds) expended and dispersed these over the two habitats to achieve the replication that would have allowed the application of ANOVA to our data. However, we decided not to do this for the following reasons. Depending on the number of 
January 2004

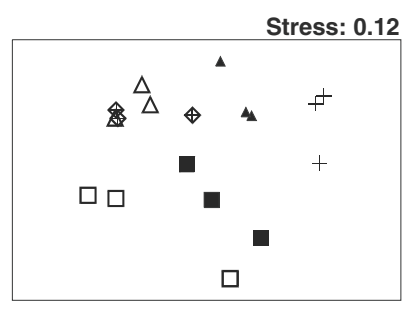

July 2004

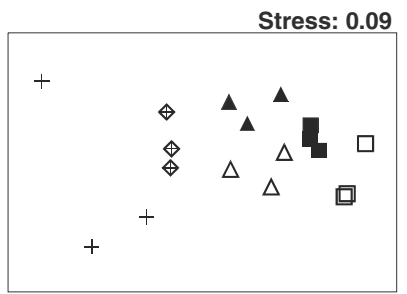

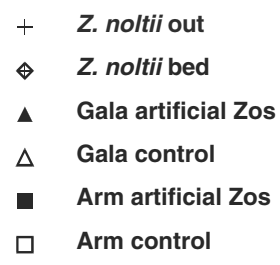

ㅁ Arm control
March 2004

Stress: 0.1

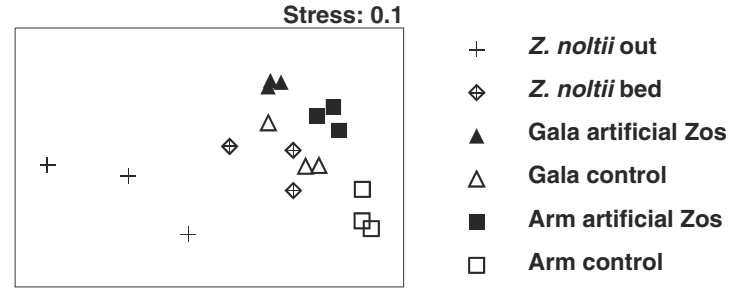

October 2004

Stress: $\mathbf{0 . 1 2}$

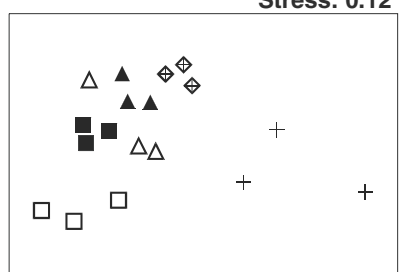

$+\quad$ Z. noltii out

$\diamond \quad$ Z. noltii bed

- Gala artificial Zos

$\triangle \quad$ Gala control

- Arm artificial Zos

$\square \quad$ Arm control

Fig. 6 Two-dimensional MDS ordination plots of macrobenthic communities

smaller plots per site, plot size would have effectively been very small, probably less than $1 \mathrm{~m}^{2}$ for $n=4$, given the relatively larger edge effects. It would be difficult to argue that plots of this scale can mimic the structural and hydrodynamic environment of seagrass beds sensu strictu or even large natural patches. Indeed, even the largest scale plots that we managed to construct had faunal assemblages that remained different from natural seagrass beds (Figs. 6, 7). We argue that smaller mimic plots would have been even less realistic. Experiments aimed at mimicking
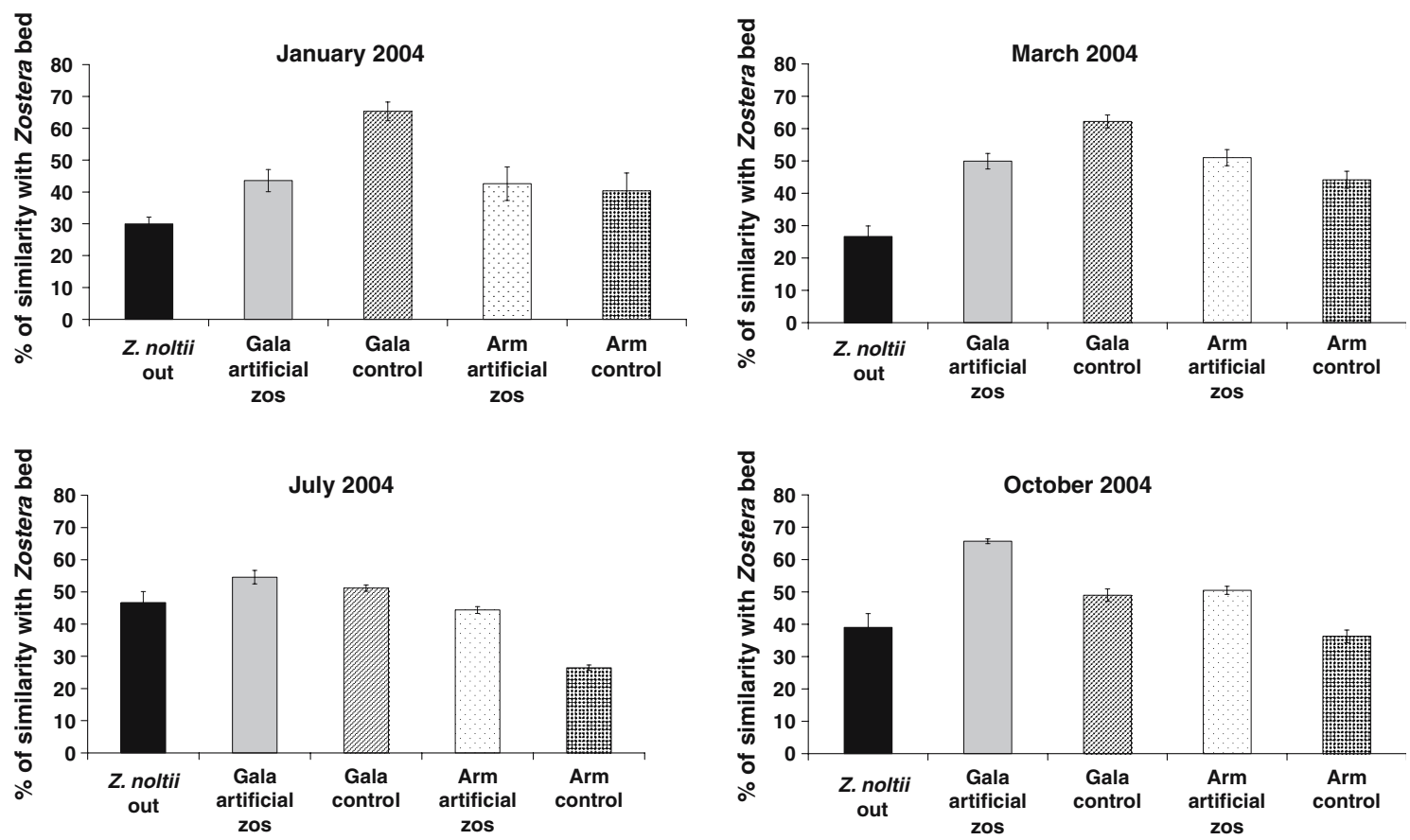

Fig. 7 Similarities between experimental plots macrobenthic communities and the natural seagrass bed 
the effects of habitats with a large spatial extent, such as seagrass beds, need to be conducted at as large a scale as possible, if they are to approach ecological realism, even if this is at the expense of replication. We believe that, for a fixed set-up cost, it is much better to have an un-replicated experiment that approaches the correct scale, than a highly replicated, small scale one that allows elegant and powerful statistical analysis but where the relevance of the outcomes are debatable.

In the present experiment, our seagrass mimics clearly changed the local sediment conditions within the experimental plots: sediment accumulated and organic matter content increased as predicted, reflecting changes in near-bed hydrography (Orth et al., 1991), and confirming the notion that seagrass canopies influence water current flow, attenuating waves and dissipating turbulence, thereby reducing sediment ressuspension and increasing the retention of sediments within the meadows, and hence the rate of detritus accumulation (Duarte, 2000).

The faunal difference between artificial seagrass units and their controls and those between the natural seagrass bed and its surrounding unvegetated sediments, were of a similar scale and we conclude that the habitat structuring effects of the artificial seagrass plots was qualitatively similar to that normally produced by a natural seagrass bed. Despite large-scale changes in the physical environment, there was some evidence of convergence of the invertebrate assemblages within the artificial seagrass plots towards that normally recorded from the natural seagrass bed, although after 12 months artificial and natural seagrass assemblages still remained substantially different. There may be several reasons for this. First, not enough time had elapsed to allow recruitment, growth and relative abundance shifts in invertebrate populations. Whilst any effects on the population structure of Hydrobia would seem to take many months to develop (due to the slow growth of the snails, see below), insufficient experimental duration is unlikely to be the complete explanation for the absence of typical seagrass taxa in seagrass mimic plots. A complementary, perhaps alternative, explanation is that environmental differences between the sites established over years of eutrophication were sufficiently great to prohibit the re-establishment of a natural seagrass assemblage if only the physical habitat structure is restored.

Hydrobia ulvae density was always higher in the Gala artificial seagrass plots than in the Gala control, possibly due to the green macroalgae (food resource) present on the mimics and also due to the heterogeneity and complexity created by the artificial plants. In January, the mean population density was much higher than in the following surveys, perhaps due to the combined effects of stronger benthic recruitment in this area and dispersion of juveniles from the natural seagrass bed. In the eutrophic area (Arm), snail density increased in the artificial seagrass plot until July when it became different from the control. In October, extensive flooding occurred and most of the snails in the artificial seagrass plot disappeared, along with the artificial seagrass shoots and the sediment was very heterogeneous (personal observations).

There were no obvious effects of seagrass mimics on Hydrobia size during the first few months of the experiment, but a greater number of larger individuals were recorded after about 9 months. We believe that this is partly explained by the growth rate of individual Hydrobia over the experimental period. Previous research (Lillebø et al., 1999; Cardoso et al., 2002) has shown that Hydrobia recruits which were present in plots at the start of the experiment (September 2003) would require at least 9 months to grow to the adult body size ( $>1.5 \mathrm{~mm}$ width). One of the recruitment peaks of $H$. ulvae is in September (see Cardoso et al., 2002) and one would not therefore expect to see significant treatment effects until July 2004. It is also possible that the appearance of large individuals in the artificial seagrass plots is due in part to the dispersion of $H$. ulvae from the surrounding area into the artificial seagrass units. This process could have been occurred some months after the beginning of the experiment, when the presence of macroalgae and microalgae growing on the units could make them more attractive for the snails.

In the natural seagrass bed, the adult snail density was always higher than in the other 
treatments, including the artificial plots. This may be explained by the generally better environmental quality of this outer estuary site (it is the least affected by eutrophication) and the improved food (epiphytes) quality provided by natural seagrasses offer, compared to that in the artificial seagrasses. Pinckney \& Micheli (1998) noted that epiphyte biomass tends to be higher on live compared to mimic blades and that species composition also differs.

Our experiment provides limited but compelling evidence that large, adult Hydrobia are not regularly found in the Gala and Arm areas of the estuary because of the lack of habitat structure provided by macrophytes, such as seagrasses. In the absence of such structure, large individuals are removed from these sites possibly due to their greater risk of dislodgment by water movement, lack of epiphytic algae, and/or predation by epibenthic crustaceans, such as crabs and shrimps, as well as shorebirds. Further investigations are required to determine which of these factors is the most important for the snails, and different factors may be different for different species. However, our study does show the importance of carrying out manipulations at the appropriate spatial scale and running them for sufficiently long duration. If we had used smaller plot sizes and run the experiment for a shorter time (many manipulative experiments in intertidal systems have typically run for only a few weeks; Raffaelli \& Moller, 2000), our findings would probably have been quite different.

Acknowledgements This paper was supported by the FCT (Portuguese Foundation for Science and Technology) through a grant attributed to P. G. Cardoso (SFRH/BD/ 5350/2001). The authors are indebted to all colleagues from IMAR-Coimbra who assisted in the field and laboratory work and to family and friends that helped in the construction of the artificial seagrass shoots.

\section{References}

Anderson, A., 1971. Intertidal activity, breeding and the floating habitat of Hydrobia ulvae in the Ythan estuary. Journal Marine Biological Association UK 51: 423-437.

Cardoso, P. G., A. I. Lillebø, M. A. Pardal, S. M. Ferreira \& J. C. Marques, 2002. The effect of different primary producers on Hydrobia ulvae population dynamics: a case study in a temperate intertidal estuary. Journal of Experimental Marine Biology and Ecology 277(2): 173-195.

Cardoso, P. G., M. A. Pardal, A. I. Lillebø, S. M. Ferreira, D. Raffaelli \& J. C. Marques, 2004. Dynamic changes in seagrass assemblages under eutrophication and implications for recovery. Journal of Experimental Marine Biology and Ecology 302: 233-248.

Cardoso, P. G., A. Brandão, M. A. Pardal, D. Raffaelli \& J. C. Marques, 2005. Resilience of Hydrobia ulvae populations to anthropogenic and natural disturbances. Marine Ecology Progress Series 289: 191-199.

Clarke, K. R. \& R. M. Warwick, 2001. Change in Marine Communities. An Approach to Statistical Analysis and Interpretation, 2nd edn. Primer-E Ltd, Plymouth.

Clarke, K. R. \& R. N. Gorley, 2001. Primer v5: User Manual/Tutorial. Primer-E Ltd, Plymouth.

Commito, J. A. \& E. M. Boncavage, 1989. Suspensionfeeders and coexisting infauna: an enhancement counterexample. Journal of Experimental Marine Biology and Ecology 125: 33-42.

Commito, J. A. \& N. M. J. A. Dankers, 2001. Dynamics of temporal and spatial complexity in European and North American soft-bottom mussel beds. In Reise, K. (ed.) Ecological Comparisons of Sediment Shores. Springer, Berlin, 39-60.

Dittmann, S., 1990. Musselbeds-amensalism or amelioration for intertidal fauna? Helgoländer Meeresuntersuchungen. 44: 335-352.

Dolbeth, M., M. A. Pardal, A. I. Lillebø, U. M. Azeiteiro \& J. C. Marques, 2003. Short- and long-term effects of eutrophication on the secondary production of an intertidal macrobenthic community. Marine Biology 143: $1229-1238$.

Duarte, C. M., 2000. Marine biodiversity and ecosystem services. Journal of Experimental Marine Biology and Ecology 250: 117-132.

Flach, E. C., 1992. Disturbance of benthic infauna by sediment-reworking activities of the lugworm Arenicola marina. Journal of Sea Research 30: 81-89.

Flach, E. C. \& A. Tamaki, 2001. Competitive bioturbators on intertidal sandflats in the European Wadden Sea and Ariake Sound, Japan. In Reise, K. (ed.) Ecological Comparisons of Sediment Shores. Springer, Berlin, 149-172.

Huxham, M., D. Raffaelli \& A. W. Pike, 1995. The effect of larval trematodes on the growth and burrowing behaviour of Hydrobia ulvae (Gastropoda: Prosobranchiata) in the Ythan Estuary, north-east Scotland. Journal of Experimental Marine Biology and Ecology 185: 1-17.

Lee, S. Y., C. W. Fong \& R. S. S. Wu, 2001. The effects of seagrass (Zostera japonica) canopy structure on associated fauna: a study using artificial seagrass units and sampling of natural beds. Journal of Experimental Marine Biology and Ecology 259(1): 23-50.

Lillebø, A. I., M. A. Pardal \& J. C. Marques, 1999. Population structure, dynamics and production of $\mathrm{Hy}$ drobia ulvae (Pennant) (Mollusca: Prosobranchia) along an eutrophication gradient in the Mondego estuary (Portugal). Acta Oecologica 20(4): 289-304. 
Marques, J. C., M. A. Pardal, S. N. Nielsen \& S. E. Jørgensen, 1997. Analysis of the properties of exergy and biodiversity along an estuarine gradient of eutrophication. Ecological Modelling 102: 155-167.

Marques, J. C., S. N. Nielsen, M. A. Pardal \& S. E. Jørgensen, 2003. Impact of eutrophication and river management within a framework of ecosystem theories. Ecological Modelling 166: 147-168.

Martins, I., M. A. Pardal, A. I. Lillebø, M. R. Flindt \& J. C. Marques, 2001. Hydrodynamics as a major factor controlling the occurrence of green macroalgal blooms in a eutrophic estuary: a case study on the influence of precipitation and river management. Estuarine Coastal and Shelf Science 52: 165-177.

Orth, R. J., K. L. Heck \& R. J. Diaz Jr, 1991. Littoral and intertidal systems in the mid-Atlantic coast of the United States. In Mathieson, A. C. \& P. H. Nienhuis (eds) Intertidal and Littoral Ecosystems. Elsevier, Amsterdam, 193-214.

Pardal, M. A., J. C. Marques, I. Metelo, A. I. Lilleb $\varnothing$ \& M. R. Flindt, 2000. Impact of eutrophication on the life cycle, population dynamics and production of Ampithoe valida (Amphipoda) along an estuarine spatial gradient (Mondego estuary, Portugal). Marine Ecology Progress Series 196: 207-219.

Pardal, M. A., P. G. Cardoso, J. P. Sousa, J. C. Marques \& D. Raffaelli, 2004. Assessing environmental quality: a novel approach. Marine Ecology Progress Series 267: $1-8$.
Pinckney, J. L. \& F. Micheli, 1998. Microalgae on seagrass mimics: does epiphyte community structure differ from live seagrasses? Journal of Experimental Marine Biology and Ecology 221: 59-70.

Planas, M. \& J. Mora, 1987. Dinámica poblacional de Hydrobia ulvae (Pennant) en la ria de Pontevedra (NO España). Cahiers de Biologie Marine 28: 447464.

Raffaelli, D., J. A. Raven \& L. J. Poole, 1998. Ecological impacts of green macroalgal blooms. Oceanography and Marine Biology: an Annual Review 36: 97-126.

Raffaelli, D. \& H. Moller, 2000. Manipulative field experiments in animal ecology: do they promise more than they can deliver? Advanced Ecological Research 30: 299-330.

Ragnarsson, S. A. \& D. Raffaelli, 1999. Effects of the mussel Mytilus edulis L. on the invertebrate fauna of sediments. Journal of Experimental Marine Biology and Ecology 241: 31-43.

Ragnarsson, S. A. \& D. Raffaelli, 2001. The effects of community dominants in the organisation of intertidal mudflats of the Ythan estuary. In Raffaelli, D., M. Solan, D. Paterson, A. L. Buck \& J. R. Pomfret (eds) Coastal Zone Topics: Process, Ecology and Management. ECSA, UK, 47-54. 